\title{
Decisions Relating to Cardiopulmonary Resuscitation: commentary 3: Degrading lives?
}

Helen Watt Linacre Centre, London

\section{Goal of medicine}

The guidelines on Decisions Relating to Cardiopulmonary Resuscitation ${ }^{1}$ begin with a reassuringly objective view of medicine: its "primary goal" is to benefit patients by "restoring or maintaining their health as far as possible, thereby maximising benefit and minimising harm". Some might want to add that medicine has several goals ${ }^{2}$ not all of which relate to promoting health; however, those who see the aim of the profession as more than consumer satisfaction will welcome the suggestion here that not just any choice counts as medicine.

In the same way, the statement which heads the next paragraph would be rejected by very few readers if "quality of life" were suitably defined. If all we mean by "quality of life" is the patient's level of wellbeing, with no suggestion that the value of his or her "being" can fall to zero or below, it is uncontroversial that "it is not an appropriate goal of medicine to prolong life at all costs with no regard to its quality or the burdens of treatment on the patient".

\section{Harms and benefits}

This is, however, an overly benign interpretation of "quality of life" observations as they appear in the guidelines. Paragraph 10.2 is explicit in saying that extending life is of no benefit to patients who are (for example) in a state of permanent unconsciousness. Again, a charitable reader might try to interpret this statement as referring only to medical benefit: benefit in terms of what the guidelines describe as the "primary goal" of medicine. It seems from the reference to experiencing benefit, however, that the guidelines are saying that this is the basis of benefit: that one cannot benefit unless one can experience the benefit in question.

This view is not well founded: there are benefits which do not require conscious experience. A person deprived of such a benefit can be harmed without being mentally affected. ${ }^{4}$ For example, lethal experiments on the profoundly mentally disabled may not affect their mental life, but will constitute harm none the less. There is injury to life and bodily integrity, which are aspects of the patient's wellbeing, even in cases where their instrumental benefit to the patient has ceased. Life and bodily integrity are of some benefit to human beings simply in themselves. If we deny this, our basis for rejecting lethal interventions on some patients will be weakened, in a way which may have serious implications for the protection of these patients.

\section{Degrading lives}

Perception of benefit is neither necessary, nor sufficient, for benefit to occur. Nor is perception of harm sufficient for harm to occur, as the guidelines later suggest (here it is past perception to which they are referring). Paragraph 10.3 states that "some people have a profound abhorrence of being kept alive in a state of total dependency or permanent lack of awareness", and that health professionals should refrain from "artificially preserving life where it is clear that the patient would consider the resulting situation to be an 'inhuman or degrading' state". The next sentence passes smoothly from perception of harm to harm itself: health professionals must not subject the patient to "inhuman or degrading" treatment (which is, apparently, any treatment which results-simply by preserving life $^{5}$-in this unwanted state).

Here it may be helpful to recall some observations of Christopher Coope on such a view of "total dependency":

"It is thought somehow undignified to be ministered to as helpless. This is, I want to argue, an unreasonable and mischievous thought, and it is especially important for doctors, nurses, and caregivers to discourage it [ . . . neither being in need, nor being helped, should be thought demeaning in itself [ . . . .] Of course, a caregiver will need to be sensitive to people's concerns, even if these concerns are unreasonable. But the encouragement of this kind of concern is a harm to all those who need this kind of help." ${ }^{\prime \prime}$ 


\section{Suicidal refusals}

Patients who refuse an intervention out of a "profound abhorrence of being kept alive" would appear to be suicidally motivated. It is not the intervention as such they seem to be trying to avoid (as futile and/or burdensome) but rather, life itself. The patient sees life as repugnant in certain situations, and wants it to be ended. Yet suicide prevention would vanish altogether if a person's own perception of the value of his or her life, and the need to end that life, were simply accepted by others. We do not normally agree with suicidal people that their lives are, or could become, worthless, so that death should be preferred. Rather, we do what we can to assist them to see their lives as having value. If the physically ill are to be treated differently from the physically well in this regard, we need to ask what this says about our own view of disability. ${ }^{7}$ Do we ourselves see disabled people's lives as "inhuman" or "degrading"-not just worthless, but of negative value? What justifies this summary assessment of such people's presence in the world?

It is clear that suicide need not involve a "positive act", but can involve an omission. It would be strange to say that it is suicide to step in front of a bus, but not to remain in front of a bus. ${ }^{8}$ In the same way, assisted suicide can also involve an omission: all that is required is that the person assisting share the intention of the suicidal person that a "worthless" life be curtailed. We can imagine, for example, a person who takes an overdose, and refuses to have cardipulmonary resuscitation (CPR) or other life-saving interventions: a doctor who "respects her refusal" with the aim of making her suicide effective will be assisting in suicide. Of course, what duties we have to prevent suicide will depend on our other responsibilities: nonintervention to prevent suicide, without the aim of facilitating suicide, is not assisted suicide, and is not wrong in all cases. If, however, we aim to assist a patient in ending her life by passive means this is no less assisted suicide than leaving a syringe by her bed.

The guidelines refer to a proxy decision maker in Scotland who has the power to refuse medical treatment on a patient's behalf. What should we say about a proxy who purposely carries out the suicidal wishes of the now-incompetent patient in refusing CPR? This is, perhaps, more like straight homicide than assisted suicide, as the patient is not suicidal at the time the proxy is acting, but is rather incompetent. A patient with Alzheimer's, who may or may not be suffering at the time, could have his life purposely ended on the grounds that he "would not have wanted to live in that condition". This shift from the patient's best interests in objective terms to the patient's previous and/or hypothetical views about the worth of his life is a subjectivisation of the patient's interests of a highly dangerous kind.

\section{Non-suicidal refusals}

Most often, a patient is not suicidal in refusing treatment, but simply considers the treatment to be not worth the burdens it involves. With very few exceptions (for example, in the interests of public health) such refusals should be respected. A competent person has prime responsibility for safeguarding health and other aspects of his or her wellbeing. Doubts do arise with regard to advance directives, since the patient is no longer competent when treatment is withheld, and since the normal standards for informed consent may not be met. However, a recent refusal by an informed, nonsuicidal and competent patient has considerable force.

\section{Overtreatment}

When it comes to receiving treatment, as the guidelines rightly say, doctors cannot be required to give treatment contrary to their clinical judgment. Interestingly, the guidelines are well disposed to satisfying patients' requests for treatment which carries "only a very small chance of success or benefit" (5.2). One can certainly think of situations where a small health benefit is socially very significant: for example, where a terminal patient wants to live long enough to see an estranged family member. In the absence of such special circumstances, which will emerge from discussions with the patient, it is, perhaps, going too far to say that "wherever possible" a wish for treatment should be respected. This is an example of how overtreatment, as well as undertreatment, can follow from too strong an emphasis on patient autonomy.

Cardiopulmonary resuscitation does not have a high success rate, and cannot be recommended across the board. It may often be withheld as unlikely to benefit the patient to any great degree, bearing in mind the burdens it imposes for the patient and for others. It may also be withheld because the patient has refused it, when he or she is competent, well-informed and is not suicidal. There is no need to have recourse to dubious theories on "degrading" lives, and the right to end such lives, to justify withholding CPR. Medicine is not about classifying patients into those who should and should not live-for example, on the basis of real or imaginary preferences for living or for dying. Rather, it is about offering such treatment as is appropriate in the situation: treatment which will benefit the patient sufficiently to justify the burdens it involves.

Helen Watt, PhD, is Research Fellow at the Linacre Centre, London.

\section{References and notes}

1 British Medical Association, the Resuscitation Council and the Royal College of Nursing. Decisions relating to cardiopulmonary resuscitation: a joint statement from the British Medical Association, the Resuscitation Council (UK) and the Royal Association, the Resuscitation Council (UK) and the Royal College of Nursing. London: British Medical

2 For example, the goal of preventing painful dysfunction-if necFor example, the goal of preventing painful dysfunction-if necnal patient with intractable pain is sedated to the point of unconsciousness). 
3 See, for example, Keown J. Restoring moral and intellectual shape to the law after Bland. Law Quarterly Review 1997;113: 481-503; Watt H. Life and death in healthcare ethics: a short introduction. London: Routledge, 2000: 33-8; Gormally L, ed. Euthanasia, clinical practice and the law. London: The Linacre Centre, 1994: 134-5; 13 Centre, 1994134-5; 138-140; The Linacre Centre. Withdrawing and withholding treatment. a response to: Withdrawing and withholding treatment: a consultation paper from the BMA's Medical Ethics Committee. London: The Linacre Centre, October 1998: 20-30.

4 Even benefits which presuppose experience can be lost without the individual experiencing this as harm. For example, an infant who dies is deprived both of "human goods" such as life which need not involve experience and of goods such as knowledge and friendship which must involve experience. See reference 1: 9-11.
5 Where brain damage occurs before CPR is attempted (10.3) such damage is not "caused" by CPR in any relevant sense. By analogy, CPR does not "cause"” cancer simply by preserving life in a patient who has cancer. The patient is not deprived of health in any aspect which he or she had before CPR, or would have had without it. Of course, CPR can itself cause harm (for example, sternal fracture) which needs to be considered in deciding whether to provide it

6 Coope CM. Death with dignity. Hastings Center Report 1997;27:38.

7 On the complexity of the doctor-patient relationship in the context of (active) assisted suicide, see Vargese FT, Kelly B. count of (active) assisted suicide, see Vargese F T, Kelly B. Countrins

8 The Linacre Centre. Human dignity, autonomy and mentally incapacitated persons: a response to Who decides?. London: The Linacre Centre, 1998: 34

\section{News and notes}

\section{Call for abstracts: XVIth International Congress of the European Society for Philosophy of Medicine and Healthcare}

The theme of the XVIth International Congress of the European Society for Philosophy of Medicine and Healthcare is European Philosophy of Healthcare and Bioethics. The congress will be held in Malta from August $21-24,2002$. Abstracts should be received before December 1, 2001.
For more information please contact: Prof $\mathrm{dr}$ Henk ten Have, secretariat ESPMH, Department of Ethics, Philosophy and History of Medicine, University Medical Center, PO Box 9101, 6500 HB Nijmegen, the Netherlands. Fax: 024 - 3540254: from abroad: ++31-24-3540254. 